\title{
Direct Adhesion to Bone Marrow Stroma via Fibronectin Receptors Inhibits Hematopoietic Progenitor Proliferation
}

\author{
Randolph W. Hurley, ${ }^{*}$ James B. McCarthy, ${ }^{\ddagger}$ and Catherine M. Verfaillie * \\ Department of $*$ Medicine and ${ }^{\ddagger}$ Laboratory Medicine, University of Minnesota, Minneapolis, Minnesota 55455
}

\begin{abstract}
In long-term bone marrow cultures, stroma-adherent progenitors proliferate significantly less than nonadherent progenitors. Thus, close progenitor-stroma interactions may serve to regulate or restrict rather than promote hematopoietic progenitor proliferation. We hypothesized that signaling through adhesion receptors on hematopoietic cells may contribute to the inhibition of proliferation observed when progenitors are in contact with stroma. We demonstrate that progenitors cultured physically separated from stroma in a transwell proliferate significantly more than progenitors adherent to stroma. Furthermore, proliferation of colony forming cells (CFC) is reduced after specific adhesion to stroma, metabolically inactivated glutaraldehyde-fixed stroma, stromal-extracellular matrix, or the COOH-terminal heparin-binding domain of fibronectin. Nonspecific adhesion to poly-L-lysine fails to inhibit CFC proliferation. That the VLA-4 integrin is one of the receptors that transfers proliferation inhibitory signals was shown using blocking anti- $\alpha 4$ monomeric $F(a b)$ fragments. Furthermore, when synthetic peptides representing specific cell attachment sites within the heparin-binding domain of fibronectin were added to Dexter-type marrow cultures, significantly increased recovery and proliferation of CFC was observed, suggesting that these peptides disrupt adhesionmediated proliferation inhibitory events. Thus, negative regulation of hematopoiesis may not only depend on the action of growth inhibitory cytokines but also on growth inhibitory signals resulting from direct adhesive interactions between progenitors and marrow stroma. (J. Clin. Invest. 1995. 96:511 -519.) Key words: cell adhesion • hematopoietic stem cell • extracellular matrix • fibronectin • cell division
\end{abstract}

\section{Introduction}

Hematopoiesis is a highly regulated process that occurs in the bone marrow $(\mathrm{BM})^{1}$ microenvironment. It can be viewed as

Address correspondence to Catherine M. Verfaillie, M.D., Dept. of Medicine, Box 480 UMHC, 420 Delaware Street SE, Minneapolis, MN 55455. Phone: 612-624-0123; FAX: 612-625-6919.

Received for publication 27 July 1994 and accepted in revised form 14 March 1995.

1. Abbreviations used in this paper: $\mathrm{BM}$, bone marrow; $\mathrm{CFC}$, colonyforming cells; CM, conditioned media; CML, chronic myelogenous leukemia; ECM, extracellular matrix; FN, fibronectin; IMDM, Iscove's modified Dulbecco's media; LTBMC, long-term bone marrow culture; VCAM, vascular cell adhesion molecule.

J. Clin. Invest.

(C) The American Society for Clinical Investigation, Inc. 0021-9738/95/07/0511/09\$2.00

Volume 96, July 1995, 511-519 the result of a balance between signals that stimulate and signals that inhibit the proliferation and differentiation of pluripotent hematopoietic progenitors (1). Hematopoietic progenitors grow in close approximation with stromal cells, and a variety of adhesion receptors are present on hematopoietic progenitors that allow interaction with receptors on stromal cells and with the stromal extracellular matrix (ECM) (2). Stromal cells produce a variety of both positive and negative growth regulatory cytokines that can influence the proliferation and differentiation of progenitors by interacting with specific cytokine receptors present on hematopoietic progenitors (1). Recently, it has been recognized that adhesion receptors, like cytokine receptors, can directly transmit signals into cells (3). Adhesion, per se, may therefore directly alter hematopoietic progenitor proliferation and differentiation. If and how adhesion regulates hematopoietic progenitor proliferation, however, is poorly understood.

Long-term stromal cultures originally described by Dexter closely mimic the BM microenvironment and have contributed substantially to our understanding of normal hematopoietic regulatory control. Using $\left[{ }^{3} \mathrm{H}\right]$ thymidine suicide assays to assess clonogenic cell proliferation, Cashman et al. (4) originally observed that progenitors adherent to stroma proliferate significantly less than nonadherent progenitors. The regulation of adherent progenitor proliferation was, at least in part, attributed to the effect of locally acting inhibitory cytokines such as TGF$\beta(1,5)$. We, on the other hand, hypothesized that progenitor proliferation may also be restricted or regulated by direct proliferation inhibitory signals transduced by adhesion receptors present on hematopoietic cells.

We recently demonstrated that progenitors can be maintained and induced to differentiate when grown separated from stroma in a transwell insert placed above a stromal layer (stroma-noncontact cultures) (6). Interestingly, significantly more colony-forming cells (CFC) are recovered from 5-wk-old stroma-noncontact cultures than from stroma-contact cultures (6). This suggests that direct contact with stroma may be required for the inhibition rather than the induction of proliferation of hematopoietic progenitors.

Of the numerous adhesive interactions between progenitors and BM stroma, interactions with fibronectin (FN) and its proteolytic fragments have been studied extensively (7-10). CFC adhere to the RGD containing $75-\mathrm{kD}$ proteolytic fragment, via the $\alpha 5 \beta 1$ integrin, and to the $33 / 66-\mathrm{kD} \mathrm{COOH}$-terminal heparin-binding fragment of FN via the $\alpha 4 \beta 1$ integrin and cell surface proteoglycans (9). More primitive progenitors, with longterm culture initiating capabilities, adhere only to the 33/66$\mathrm{kD} \mathrm{COOH}$-terminal heparin-binding domain of $\mathrm{FN}(9)$. Within the heparin binding domain of FN, several cell attachment sites have been identified. These include the CS1 site, containing the LDV sequence important for $\alpha 4 \beta 1$ integrin mediated adhesion, and two heparin binding sites termed $\mathrm{FN}-\mathrm{C} / \mathrm{H} \mathrm{I}$ and $\mathrm{FN}-\mathrm{C} / \mathrm{H}$ II, which can mediate adhesion of progenitors through CD44 and cell-surface proteoglycans $(11-13)$. Studies in other bio- 
logical systems have demonstrated that adhesion to FN may directly alter the proliferative behavior of cells in both a positive and negative fashion $(14,15)$. Therefore, since synthetic FN peptides as well as antiintegrin antibodies inhibit progenitor adhesion to BM stroma $(10,16-18)$, we hypothesized that FN present in stromal layers may serve as one of the ligands responsible for the inhibition of stroma-adherent progenitor proliferation. In this report, we use several strategies to demonstrate that direct adhesion to BM stroma through receptors important for progenitor adhesion to FN inhibits hematopoietic progenitor proliferation.

\section{Methods}

\section{Hematopoietic cell separation}

Bone marrow was obtained from the posterior iliac crest of healthy volunteers under guidelines approved by the Human Subjects Committee at the University of Minnesota. Lineage-negative $\left(\mathrm{Lin}^{-}\right)$cells were obtained by sequential Ficoll-Hypaque separation, counterflow elutriation, sheep erythrocyte rosetting, and immunomagnetic bead depletion as previously described (6). $\mathrm{Lin}^{-} \mathrm{CD} 34^{+} \mathrm{HLA}-\mathrm{DR}^{+}\left(\mathrm{DR}^{+}\right)$and Lin $^{-}$CD34 ${ }^{+} \mathrm{HLA}^{-D R^{-}}\left(\mathrm{DR}^{-}\right)$cells were selected by FACS. DR ${ }^{-}$cells were used to initiate long-term stroma-contact, stroma-noncontact, and conditioned-media cultures, whereas $\mathrm{DR}^{+}$cells were used to assess proliferation of committed progenitors.

\section{Stroma-dependent cultures}

Stromal layers. Stromal layers were generated as described (18). After irradiation, stroma was subcultured in 6- and 24-well plates (Costar, Cambridge, MA) at a concentration of $3.5 \times 10^{5} \mathrm{cells} / \mathrm{ml}$. Long-term BM culture (LTBMC) media consisted of Iscove's modified Dulbecco's media (IMDM, Gibco Laboratories, Grand Island, NY) with $12.5 \%$ FCS (Hyclone Laboratories, Logan, UT), 12.5\% horse serum (Terry Fox Laboratories, Vancouver, British Columbia), $2 \mathrm{mM}$ L-glutamine, $1,000 \mathrm{U} / \mathrm{ml}$ penicillin, $100 \mathrm{U} / \mathrm{ml}$ streptomycin (Gibco Laboratories), and $10^{-6} \mathrm{M}$ hydrocortisone (A-Hydrocort, Abbott Laboratories, North Chicago, IL).

Induction of CFC proliferation. To induce CFC proliferation, 100,000 freshly sorted $\mathrm{DR}^{+}$cells were plated in a transwell insert above BM stroma present in a six-well plate. After 3-4 d, DR ${ }^{+}$progeny were recovered and used to assess the effect of adhesion on committed progenitor proliferation.

Stroma-contact cultures. Standard Dexter-type stroma-contact cultures were initiated by plating 5,000-10,000 $\mathrm{DR}^{-}$cells in $1 \mathrm{ml}$ LTBMC media onto stromal layers in 24-well plates as previously described (6). In selected experiments, $\mathrm{DR}^{-}$cells were preincubated for $30 \mathrm{~min}$ with synthetic FN peptides $(200 \mu \mathrm{g} / \mathrm{ml})$ before plating in stroma-contact cultures. Additional peptide $(200 \mu \mathrm{g} / \mathrm{ml})$ was added three times per week for the duration of the cultures.

Stroma-noncontact cultures. 5,000 sorted $\mathrm{DR}^{-}$cells were placed in a transwell chamber above stroma subcultured in 24-well plates (6). In some experiments, $\mathrm{DR}^{-}$cells were preincubated with $200 \mu \mathrm{g} / \mathrm{ml}$ of FN peptides before plating in long-term stroma-noncontact cultures. Additional peptide $(200 \mu \mathrm{g} / \mathrm{ml})$ was added to these cultures three times per week.

Conditioned-media cultures. 5,000 $\mathrm{DR}^{-}$cells were plated in transwell inserts placed in empty wells. Culture media consisted of conditioned media (CM) collected from T150 flasks containing irradiated stromal layers. After centrifugation at $400 \mathrm{~g}$ for $10 \mathrm{~min}$ (to remove cellular debris), $0.8 \mathrm{ml}$ of $\mathrm{CM}$ was placed in the bottom wells below the transwell inserts. Freshly obtained CM was replaced in the wells 6 $\mathrm{d} / \mathrm{wk}$ for the 5-wk duration of the cultures. In some experiments DR ${ }^{-}$ cells were preincubated with $200 \mu \mathrm{g} / \mathrm{ml}$ of FN peptides for $30 \mathrm{~min}$ before plating in the transwells. Additional peptide $(200 \mu \mathrm{g} / \mathrm{ml})$ was added directly to the cultures three times per week for the 5-wk duration of the cultures. Alternatively, synthetic FN peptides were added thrice weekly to the stroma containing culture vessel $(200 \mu \mathrm{g} / \mathrm{ml})$, and the resultant $\mathrm{CM}$ removed and used to culture $\mathrm{DR}^{-}$cells in transwell inserts.

Maintenance of cultures. All cultures were maintained in a humidified atmosphere at $37^{\circ} \mathrm{C}$ and $5 \% \mathrm{CO}_{2}$. Stroma-contact cultures were fed at weekly intervals by removing one half of the cell-free supernatant and replacing it with fresh LTBMC media. Stroma-noncontact cultures were fed weekly by removing one half of the media in the bottom wells and replacing it with fresh media. Stromal flasks used to generate CM for CM cultures were fed weekly with one half media change.

Evaluation of long-term cultures. On days 2, 4, and 7 during week 5 of long-term culture, separate wells were sacrificed and evaluated in short-term methylcellulose assays for the presence of committed progenitors and for progenitor proliferation by $\left[{ }^{3} \mathrm{H}\right]$ thymidine suicide assay. For stroma-contact cultures, the nonadherent cells were removed with four gentle washes with warm IMDM. The cells in the adherent stromal layer were recovered after brief trypsinization (6).

\section{Short-term methylcellulose progenitor cultures}

Cells recovered from the adherent and nonadherent fractions of stromacontact cultures, from transwell inserts of stroma-noncontact and CM cultures, or cells recovered in the adherent and nonadherent fraction of adhesion assays were plated in methylcellulose progenitor media as previously described (6). Wells were scored for the presence of CFC (burst-forming progenitor cells, CFU-GM, and CFU-mix) after $14 \mathrm{~d}$ in culture.

\section{Adhesive substrates}

Glutaraldehyde fixation of stromal layers. Irradiated stromal layers were treated with 2\% glutaraldehyde (Sigma Chemical Co., St. Louis, MO) in $0.1 \mathrm{M}$ Sorenson's buffer for $5 \mathrm{~min}$ and washed five times with IMDM (19). Metabolic inactivation was ensured by Trypan-blue exclusion and by the cessation of lactate production (Quantitative Enzymatic Determination Kit, Sigma Diagnostics, St. Louis, MO).

Extracellular matrix. Irradiated stromal layers were treated consecutively for $5 \mathrm{~min}$ with $1 \%$ Triton-X100 (Sigma) and $1 \mathrm{M} \mathrm{NaCl}$, each containing $2 \mathrm{mM}$ PMSF, (Sigma), followed by extensive washing with PBS.

Ligand-coated wells. 24-well plates were incubated overnight at $4^{\circ} \mathrm{C}$ with $500 \mu \mathrm{l}$ of $1 \%$ BSA ( $99 \%$ fat free, Sigma) in PBS, $50 \mu \mathrm{g} / \mathrm{ml}$ of the $\mathrm{COOH}$-terminal 33/66-kD heparin-binding domain of FN in Voller's buffer, or $10 \mu \mathrm{g} / \mathrm{ml}$ poly-L-lysine (Sigma) in Voller's buffer. Wells were washed with PBS and blocked with $1 \%$ BSA before adhesion assays.

\section{Adhesion assays}

Actively proliferating CFC recovered from 4-d-old stroma-noncontact cultures initiated with $\mathrm{DR}^{+}$cells were washed in warm IMDM, resuspended at $5,000 \mathrm{cells} / \mathrm{ml}$ in LTBMC media, and allowed to adhere to an adhesive substrate in 24-well plates for $6 \mathrm{~h}$. In some experiments, $50 \mu \mathrm{g} / \mathrm{ml}$ of neutralizing anti-TGF- $\beta$ antibody or normal chicken IgG control ( $R \& D$ Systems, Minneapolis, MN) was added to the cells before plating on nonfixed stroma or glutaraldehyde fixed stroma. In some experiments, cells were incubated with $10 \mu \mathrm{g} / \mathrm{ml}$ of monomeric $\mathrm{F}(\mathrm{ab})$ fragments of the mouse monoclonal anti- $\alpha 4$ antibody, $\mathrm{HP} 2 / 4$, or $10 \mu \mathrm{g} /$ $\mathrm{ml}$ of mouse IgG for $30 \mathrm{~min}$ at room temperature before plating on stromal layers or poly-L-lysine-coated wells. Nonadherent cells were removed with four consecutive gentle washings with warm IMDM. Adherent cells were removed separately after brief trypsinization (6). Visual inspection ensured that all adherent cells were recovered from the wells. Adherent and nonadherent CFC were either assessed for their proliferation by $\left[{ }^{3} \mathrm{H}\right]$ thymidine suicide assay or plated directly in shortterm methylcellulose progenitor cultures to enumerate CFC. Percent adhesion was calculated as $\%$ adhesion $=$ adherent $\mathrm{CFC} /$ nonadherent CFC + adherent CFC $\times 100 \%$.

\section{$\left.{ }^{3} \mathrm{H}\right]$ Thymidine suicide assay}

Proliferation of CFC was assessed with a $\left[{ }^{3} \mathrm{H}\right]$ thymidine suicide assay based on methods reported in the literature $(4,20)$. Cells recovered in 
the adherent and nonadherent fraction of stroma-contact cultures, from stroma-noncontact and CM cultures, or in the adherent and nonadherent fraction of adhesion assays were washed in warm serum-free IMDM and then incubated at $37^{\circ} \mathrm{C}$ for $20 \mathrm{~min}$ with or without $20 \mu \mathrm{Ci} / \mathrm{ml}$ of $\left[{ }^{3} \mathrm{H}\right]$ thymidine (specific activity $6.7 \mathrm{Ci} / \mathrm{mmol}$, DuPont, Boston, MA). Cells were then washed with $10 \mathrm{ml}$ cf excess cold thymidine ( $500 \mu \mathrm{g}$ ) $\mathrm{ml}$ ) (Sigma) before plating in methylcellulose assays. The percentage of progenitors in S-phase was expressed as the percentage of clonogenic cell kill: \% CFC kill $=($ CFC untreated population $)-\left(\right.$ CFC ${ }^{3} \mathrm{H}$-thymidine population $) \times 100 \% /(\mathrm{CFC}$ untreated population $)$. In control experiments, incubation of cells simultaneously with $\left[{ }^{3} \mathrm{H}\right]$ thymidine and excess cold thymidine or with excess cold thymidine only resulted in similar cell kill, suggesting specificity of clonogenic cell kill. That trypsin used to recover adherent CFC did not affect progenitor proliferation was demonstrated in experiments in which cells kept in suspension during the 6-h adhesion assay were treated with $0.05 \%$ trypsin (Sigma) for 5 min before $\left[{ }^{3} \mathrm{H}\right]$ thymidine suicide assay. No effect on percent CFC in S-phase was seen. Most $\left[{ }^{3} \mathrm{H}\right]$ thymidine suicide assays were performed in duplicate or triplicate and demonstrated a high degree of correlation (correlation coefficient 0.81 ).

\section{Purification of FN fragments and peptides}

Human plasma FN was purified as a byproduct of factor VIII production by sequential ion exchange chromatography. The 33/66-kD $\mathrm{COOH}-$ terminal heparin-binding fragment was purified from short-term (15 min) tryptic/catheptic digests of FN by sequential heparin and antibody affinity chromatography as previously described (12). Purity was verified by SDS-PAGE and Coomassie brilliant blue staining.

Peptides from the $\mathrm{COOH}$-terminal heparin binding domain of fibronectin were synthesized at the Microchemical Facility of the University of Minnesota as previously described (12). Synthesized peptides included heparin-binding peptide I, FN-C/H I ( amino acid sequence YEKPGSPPREVVPRPRPGV), heparin-binding peptide II, FN-C/H II (KNNQKSEPLIGRTKKT), and CS1 (DELPQLVTLPHPNLHPGEILDVPST). A scrambled version of FN-C/H II (KEPTKTGIRQNKSKNL) was used as control. The sequences use the single amino acid code (K, lysine; $R$, arginine; $H$, histidine; $E$, glutamic acid; $D$, aspartic acid; Q, glutamine; N, asparagine; P, proline; G, glycine; $S$, serine; T, threonine; V, valine; I, isoleucine; $\mathrm{L}$, leucine; $\mathrm{Y}$, tyrosine).

\section{Monoclonal anti- $\alpha 4 F(a b)$ fragments and $\operatorname{Ig} G$}

Mouse monoclonal anti- $\alpha 4$ integrin ascites (clone HP2/4) was a generous gift from Elizabeth Wayner (University of Minnesota, Minneapolis, $\mathrm{MN}$ ). Purified HP2/4 IgG and monomeric F(ab) fragments were obtained using a commercially available kit (Pierce, Rockford, IL). Purity was assessed by electrophoresis on an $8 \%$ SDS-PAGE gel followed by staining with Coomassie brilliant blue. Mouse IgG was from Sigma.

\section{Statistical methods}

Values are expressed as the means \pm SEM. Significance values were determined using a two-tailed Student's $t$ test. Correlation was determined by Spearman method.

\section{Results}

Proliferation of progenitors in long-term cultures. We have previously demonstrated that increased numbers of CFC are recovered after 5-wk long-term marrow cultures when progenitors are grown separated from stroma (stroma-noncontact cultures) than when progenitors are grown in direct contact with marrow stroma (in standard Dexter-type stroma-contact cultures) (6). To determine whether the increased recovery of CFC from stroma-noncontact cultures was the result of continuous or increased progenitor proliferation, we performed $\left[{ }^{3} \mathrm{H}\right]-$ thymidine suicide assays on adherent and nonadherent CFC from stroma-contact cultures and on CFC present in transwell

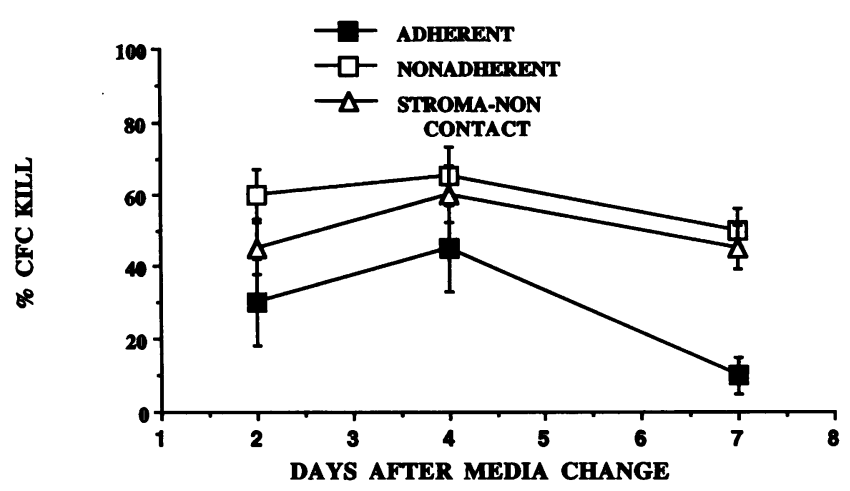

Figure 1. Proliferation of progenitors in long-term cultures. 5,000 DR cells $(n=4)$ were grown in stroma-contact and stroma-noncontact cultures for 5 wk. On days 2, 4, and 7 after the week 5 media change, adherent and nonadherent cells were removed from stroma-contact cultures and from transwells of stoma-noncontact cultures. Progenitor proliferation was assessed via $\left[{ }^{3} \mathrm{H}\right]$ thymidine suicide assay. The total number of CFC present during week 5 in the adherent layer of stromacontact cultures $=26 \pm 4$, in the nonadherent layer of stroma-contact cultures $=27 \pm 4$, and in stroma-noncontact cultures $=219 \pm 40$. Statistical analysis: comparison of proliferation (\% kill) of adherent CFC vs. nonadherent CFC or CFC in stroma-noncontact cultures on day $7, P$ $=0.05$.

inserts of stroma-noncontact cultures (Fig. 1). Consistent with our previously reported findings, significantly more CFC were recovered after $5 \mathrm{wk}$ from stroma-noncontact cultures compared with stroma-contact cultures $(P<0.01)$. $\left[{ }^{3} \mathrm{H}\right]$ Thymidine suicide assays demonstrated that CFC present in the adherent layer of stroma-contact cultures were recruited into cycle 2-4 d after a $50 \%$ media change $(45 \pm 10 \%$ kill ) and returned to a quiescent state on day 7 after feeding ( $10 \pm 5 \%$ kill), whereas nonadherent CFC proliferated continuously throughout the week after media change (50-65\% kill). These results are similar to those reported by other investigators $(4,5)$. In contrast, CFC present in stroma-noncontact cultures continued to proliferate throughout the week (45-60\% kill), much like nonadherent CFC in standard stroma-contact cultures. These studies indicated that inhibition of CFC proliferation in the adherent layer may be responsible for the lower CFC recovery from stroma-contact cultures. Inhibition of proliferation of adherent CFC may be the result of stromal produced locally acting negative-regulatory cytokines or, alternatively, may be the result of direct signal transduction through adhesion receptors present on hematopoietic cells.

Adhesion of actively proliferating progenitors to BM stroma inhibits progenitor proliferation. We developed a glutaraldehyde-fixed stromal model to separate the effects on progenitor proliferation of adhesion itself from the effects of negative regulatory growth factors. Brief glutaraldehyde fixation metabolically inactivates stroma (as assessed by failure to exclude Trypan blue and cessation of lactate production). ELISA studies demonstrated that glutaraldehyde fixation did not destroy the ability of monoclonal antibodies to detect cell surface adhesion molecules such as vascular cell adhesion molecule (VCAM), intercellular adhesion molecule, or endothelial leukocyte adhesion molecule, and ECM proteins such as FN and thrombospondin (data not shown). Furthermore, these adhesive ligands remained functional since burst-forming progenitor cells and CFU-GM adhered, albeit to a lesser extent, to glutaraldehyde- 
$\mathbf{A}$

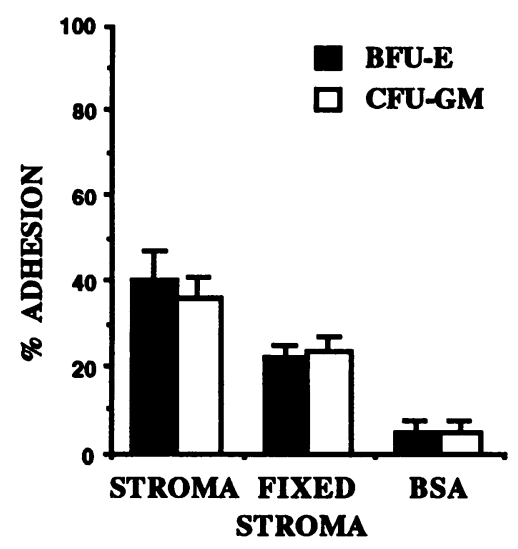

$\mathbf{C}$

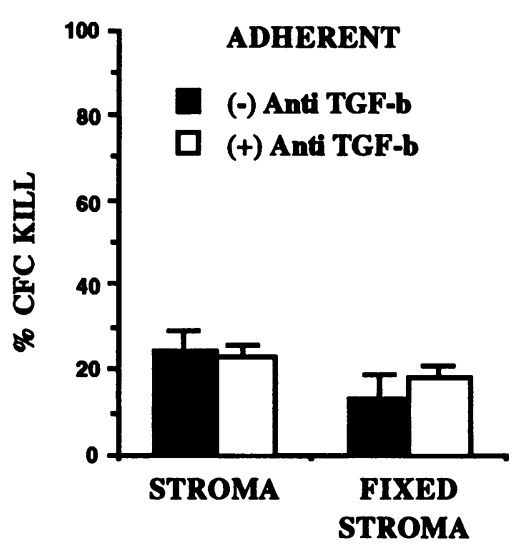

B

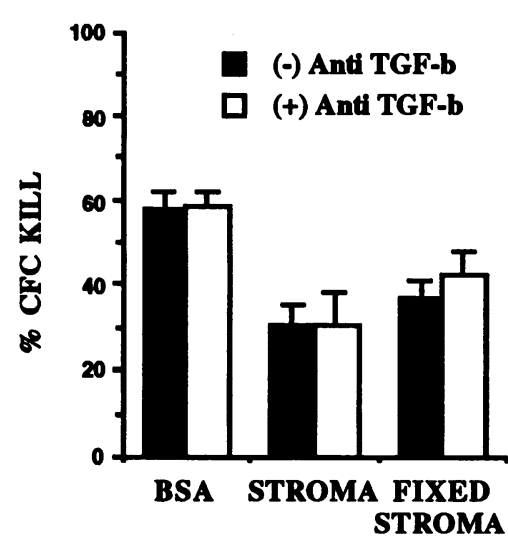

D

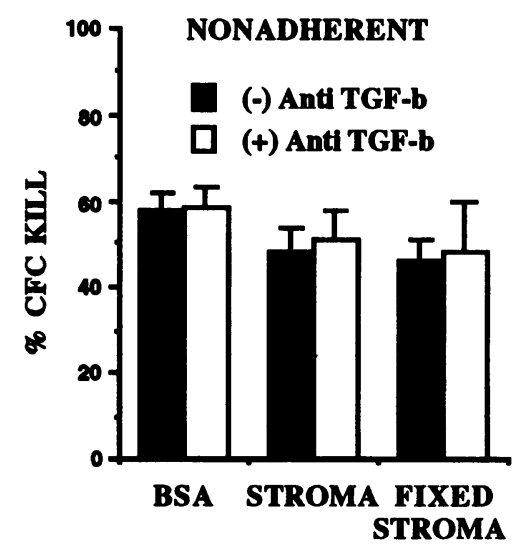

Figure 2. Adhesion to marrow stroma or glutaraldehyde-fixed stroma inhibits progenitor proliferation. Progeny of 5,000 $\mathrm{DR}^{+}$cells ( $n$ $=6$ ) recovered from 4-d-old stroma-noncontact cultures were grown for $6 \mathrm{~h}$ on unfixed stroma, glutaraldehyde-fixed stroma, or BSA-coated wells. In some experiments ( $n$ $=4$ ) cells were also incubated with or without $50 \mu \mathrm{g} / \mathrm{ml}$ of neutralizing antibodies to TGF- $\beta$ or control chicken IgG before adhesion. Adherent and nonadherent CFC were recovered and enumerated in methylcellulose progenitor assays to assess adhesion of CFC to the various substrates $(A)$, or subjected to $\left[{ }^{3} \mathrm{H}\right]$ thymidine suicide assay to assess proliferation of all CFC recovered in both the adherent and nonadherent fraction $(B)$, or proliferation of CFC in the adherent $(C)$ and nonadherent $(D)$ fractions separately. Total number of CFC present per 5,000 $\mathrm{DR}^{+}$cells: stroma, $243 \pm 15$; stroma + anti-TGF- $\beta$, $245 \pm 18$; fixed stroma, $228 \pm 29$; fixed stroma + anti-TGF- $\beta, 208 \pm 14$; BSA, $249 \pm 20$; BSA + anti-TGF- $\beta, 212 \pm 32$. Statistical analysis: comparison between CFC proliferation (\% kill) in BSA-coated wells and in stromal wells or fixed stromal wells $(B), P$ $<0.01$. Comparison of proliferation of adherent CFC and nonadherent CFC ( $C$ and $D)$ : stroma and fixed stroma, $P<0.01$. fixed stroma than to untreated stroma $(22 \pm 3 \%$ and $24 \pm 3 \%$ adhesion, respectively, compared with $41 \pm 9 \%$ and $35 \pm 5 \%$ ), whereas they did not adhere to BSA-coated wells ( $<10 \%$ adhesion) (Fig. $2 \mathrm{~A}$ ).

To assess the effect of adhesion on progenitor proliferation, actively proliferating CFC recovered from 4-d-old stroma-noncontact cultures initiated with $\mathrm{DR}^{+}$cells, were plated on unfixed stromal layers, glutaraldehyde-fixed stromal layers, or BSAcoated control wells. After $6 \mathrm{~h}$, adherent and nonadherent cells were removed and proliferation assessed with a $\left[{ }^{3} \mathrm{H}\right]$ thymidine suicide assay. Since TGF- $\beta$ has been identified as an important negative regulatory cytokine produced by stroma (1), we performed these experiments in the presence and absence of neutralizing antibodies against TGF- $\beta$. CFC recovered from 4 -dold stroma-noncontact cultures continued to proliferate $(58 \pm 4 \%$ kill) when plated for $6 \mathrm{~h}$ in BSA-coated wells (Fig. $2 \mathrm{~B}$ ). However, CFC proliferation was significantly reduced ( $31 \pm 5 \%$ kill, $P<0.01)$ after coculture for $6 \mathrm{~h}$ with untreated stroma regardless of the presence of neutralizing anti-TGF- $\beta$ antibodies. A similar reduction in proliferation was observed when
CFC were plated on glutaraldehyde-fixed stroma ( $37 \pm 4 \%$ kill, $P<0.01)$. Examination of adherent and nonadherent CFC separately revealed that reduced overall proliferation was due to progenitor adhesion to the stromal substrate. Adherent CFC proliferated significantly less (13-24\% kill) (Fig. $2 C$ ) than nonadherent CFC in stromal wells or CFC in BSA-coated wells (48-59\% kill) (Fig. $2 D$ ).

The reduced proliferation of adherent CFC could be due to selective adhesion of a nonproliferating subpopulation of CFC. However, the overall proliferation of CFC (both nonadherent and adherent, Fig. $2 B$ ) cocultured with stroma or fixed stroma was reduced compared with the proliferation of CFC grown in BSA-coated wells. Furthermore, the fraction of nonadherent CFC in S-phase recovered from stromal wells was equivalent to the fraction of CFC in S-phase recovered from BSA-coated wells. This demonstrated further that reduced proliferation of the adherent CFC population was not the result of selective adhesion of nonproliferating CFC. The decreased proliferation of stroma-adherent CFC could also be due to selective recovery of nonproliferating progenitors. However, light microscopic in- 


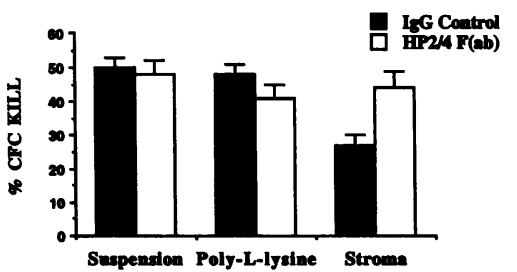

cultures $(n=6)$ were removed from transwell inserts and incubated for 30 min with $10 \mu \mathrm{g} / \mathrm{ml}$ of HP2/4 monomeric $\mathrm{F}(\mathrm{ab})$ fragments or mouse IgG before plating on stromal layers or poly-L-lysine-coated wells. Cells maintained in suspension served as controls. After $6 \mathrm{~h}$ cells were recovered and CFC proliferation assessed with a $\left[{ }^{3} \mathrm{H}\right]$ thymidine suicide assay. CFC/5,000 cells: suspension, $221 \pm 15$; stroma, $211 \pm 14$; poly-L-lysine, $225 \pm 17$. Statistical analysis: comparison of proliferation of CFC maintained in suspension with that of CFC in contact with stroma, $P<0.01$. Comparison of proliferation of CFC in contact with stroma treated with $\mathrm{HP} 2 / 4 \mathrm{~F}(\mathrm{ab})$ with that of CFC treated with mouse IgG, $P=0.01$.

spection after trypsinization demonstrated that all cells were recovered from the wells. In addition, the total number of CFC recovered from adherent and nonadherent fractions of stromal cultures was similar to that recovered from BSA-coated wells, indicating that all CFC were recovered from the stromal wells. The decreased proliferation of stroma-adherent CFC could also be caused by the short-term trypsinization used to recover adherent cells from stromal wells. However, control experiments in which $\mathrm{DR}^{+}$cells in suspension were subjected to a 5-min trypsin treatment demonstrated no effect on CFC proliferation. Our studies indicate, therefore, that CFC proliferation is reduced when cultured for $6 \mathrm{~h}$ in contact with stroma. The reduced proliferation is also observed when CFC are cocultured with a metabolically inactive stromal substrate incapable of proliferation-inhibitory cytokine production even in the presence of anti-TGF- $\beta$ antibodies. Since the reduction in proliferation occurred primarily in the fraction of CFC adherent to the stromal substrate, this indicates that proliferation-inhibition may be caused by direct progenitor adhesion to stromal cell expressed ligands or ECM components.

Anti- $\alpha 4$ integrin $F(a b)$ fragments block adhesion-mediated inhibition of progenitor proliferation. We and others have identified the $\alpha 4 \beta 1$ integrin as one of the receptors responsible for progenitor adhesion to stroma $(8-10,16,17)$. To examine if the adhesion-mediated inhibition of progenitor proliferation involves $\alpha 4$ integrin interactions, we performed adhesion assays in the presence of monomeric $\mathrm{F}(\mathrm{ab})$ fragments of the monoclonal anti- $\alpha 4$ integrin antibody, HP2/4. Actively proliferating CFC recovered from 4-d-old stroma-noncontact cultures were incubated with either $10 \mu \mathrm{g} / \mathrm{ml}$ of anti- $\alpha 4 \mathrm{~F}(\mathrm{ab})$ fragments or $10 \mu \mathrm{g} / \mathrm{ml}$ of control mouse IgG before plating on stromal layers. Cells incubated with mouse IgG or with anti- $\alpha 4 \mathrm{~F}(\mathrm{ab})$ fragments were also plated on poly-L-lysine-coated wells or maintained in suspension during the 6-h adhesion assay. After 6 $\mathrm{h}$, cells present in stroma or poly-L-lysine-coated wells were removed after brief trypsinization and the proliferative status of CFC examined via $\left[{ }^{3} \mathrm{H}\right]$ thymidine suicide assays. Recovery of CFC from all cultures was equivalent.

CFC proliferation was significantly reduced (27 $\pm 4 \%$ kill) when $\mathrm{DR}^{+}$progeny pretreated with mouse IgG were cocultured for $6 \mathrm{~h}$ with stroma compared with cells maintained in suspension during the 6-h adhesion assay $(50 \pm 3 \%$ kill, $P=0.01$ ) (Fig. 3 ). Pretreatment of $D R^{+}$cells with anti- $\alpha 4 \mathrm{~F}(\mathrm{ab})$ fragments did not significantly alter the proliferation of CFC kept in suspension. However, pretreatment of $\mathrm{DR}^{+}$cells with anti- $\alpha 4 \mathrm{~F}(\mathrm{ab})$ fragments before coculture with stroma prevented the adhesionmediated inhibition of CFC proliferation. This indicates that signaling through the $\alpha 4$ integrin may be important for transmitting proliferation inhibitory signals to hematopoietic progenitors. This therefore implicates the extracellular matrix molecule, FN, or the stromal-cell surface adhesion molecule, VCAM, as stromal adhesive ligands responsible for this proliferation-inhibitory effect. To demonstrate further that the inhibition of proliferation is due to specific ligand-receptor interactions, we plated $\mathrm{DR}^{+}$on poly-L-lysine-coated surfaces. $41 \%$ of CFC adhered to poly-L-lysine. As for stroma-adherent CFC, poly-L-lysineadherent CFC were recovered after brief trypsinization. Equivalent numbers of CFC were recovered from suspension cultures and poly-L-lysine-or stroma-coated wells. We demonstrate that CFC cultured on poly-L-lysine continued to actively proliferate regardless of the presence of anti- $\alpha 4 \mathrm{~F}(\mathrm{ab})$ antibody fragments $(41 \pm 4 \%$ kill $)$. This demonstrates that nonspecific adhesion did not inhibit proliferation. This also supports the notion that brief trypsinization was not responsible for the reduction in proliferation of stroma-adherent CFC.

Adhesion to stoma-derived ECM and the heparin binding domain of FN inhibits progenitor proliferation. To determine whether the ECM molecule, FN, is one of the stromal ligands capable of transmitting proliferation inhibitory signals to hematopoietic progenitors, we examined CFC proliferation after coculture with stroma-derived ECM or with the $\mathrm{COOH}$-terminal heparin-binding domain of FN. Progeny of $\mathrm{DR}^{+}$cells recovered from transwell inserts of 4-d-old stroma-noncontact cultures were plated on stroma-derived ECM, in wells coated with the $33 / 66-\mathrm{kD}$ heparin-binding domain of FN or in poly-L-lysinecoated wells. After $6 \mathrm{~h}$ nonadherent cells were removed and adherent cells were recovered by brief trypsinization. $41 \%$ of CFC adhered to poly-L-lysine-coated wells, $12 \pm 6 \%$ to stromalECM, and $24 \pm 2 \%$ to the heparin-binding domain of FN. Cells kept in suspension for the 6-h duration of the adhesion assay as well as adherent and nonadherent cells recovered from the adhesion assays were subjected to $\left[{ }^{3} \mathrm{H}\right]$ thymidine suicide assay to assess CFC proliferation. Equivalent numbers of CFC were recovered from suspension cultures as from ECM, FN, or polyL-lysine-coated wells. The proliferation of CFC recovered from either the nonadherent or adherent fraction of poly-L-lysinecoated wells was not significantly different than the proliferation of CFC maintained in suspension ( $54 \pm 6 \%$ kill). In contrast, proliferation of ECM-adherent CFC $(8 \pm 5 \%$ kill $)$ and CFC adherent to the heparin-binding domain of FN $(18 \pm 5 \%$ kill $)$ was significantly reduced $(P=0.01)$ (Fig. 4$)$. These studies indicate that the heparin-binding domain of FN may be one of the ligands responsible for the inhibition of CFC proliferation observed when progenitors are cultured in contact with stroma.

Addition of synthetic FN peptides to long-term cultures disrupts adhesion-mediated proliferation inhibition. To demonstrate further that adhesion to the heparin-binding domain of FN constitutes a negative regulatory signal for progenitor proliferation, we next examined whether disruption of progenitor-FN interactions in Dexter-type long-term marrow cultures would disrupt this proliferation-inhibitory effect and result in increased CFC recovery and proliferation. We used synthetic FN peptides, termed FN-C/H I, FN-C/H II, and CS1, which represent specific cell attachment sites within the heparin-binding domain of FN, to disrupt progenitor-FN interactions. Freshly sorted DR ${ }^{-}$ 


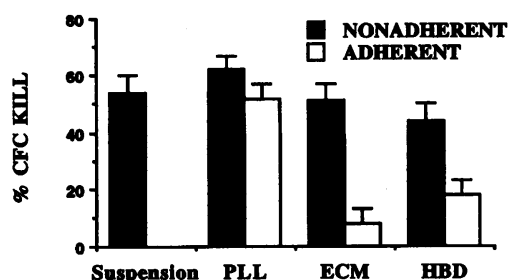
L-lysine-coated wells ( $P L L)$, stromal ECM, or wells coated with the heparin-binding domain of FN $(H B D)$. After $6 \mathrm{~h}$, proliferation of CFC maintained in suspension and proliferation of adherent and nonadherent CFC was determined via $\left[{ }^{3} \mathrm{H}\right]$ thymidine suicide assay. $\mathrm{CFC} / 5000 \mathrm{DR}^{+}$ cells: suspension, $227 \pm 27$; poly-L-lysine-coated, 234 \pm 20 ; ECM, $205 \pm 11$; heparin-binding domain, $220 \pm 22$. Statistical analysis: comparison between proliferation (\% kill) of CFC adherent to poly-L-lysine and CFC adherent to ECM or to the heparin-binding domain of FN, $P$ $<0.01$.

cells, a population enriched for long-term culture initiating cells, were preincubated with $200 \mu \mathrm{g} / \mathrm{ml}$ of $\mathrm{FN}-\mathrm{C} / \mathrm{H} \mathrm{I}, \mathrm{FN}-\mathrm{C} / \mathrm{H}$ II, or CS1 before plating in long-term stroma-contact cultures. A scrambled version of $\mathrm{FN}-\mathrm{C} / \mathrm{H}$ II and untreated wells served as controls. Additional peptide was added three times per week. On the 7th $d$ after feeding during week 5 of culture, we examined total CFC recovery by replating $\mathrm{DR}^{-}$progeny in methylcellulose progenitor cultures. We also examined the proliferative status of adherent CFC by $\left[{ }^{3} \mathrm{H}\right]$ thymidine suicide assay. The continuous presence of either $\mathrm{FN}-\mathrm{C} / \mathrm{H}$ I, FN-C/H II, or CS1 in long-term stroma-contact cultures significantly increased the overall recovery of CFC $(P<0.05)$ compared with untreated wells or wells to which scrambled peptide was added (Fig. $5 \mathrm{~A}$ ). Furthermore, the continuous presence of these FN peptides resulted in increased proliferation of adherent progenitors when evaluated at day 7 after feeding during week 5 of growth in long-term cultures (FN-C/H I $P=0.05$, FN-C/H II $P=0.03$, CS1 $P=0.036$ ) (Fig. $5 A$ ). This suggests that critical events necessary for adhesion-mediated proliferation inhibition may have been disrupted, therefore resulting in increased CFC proliferation and recovery.

We used CM cultures to exclude the possibility that FN peptides either directly stimulated CFC proliferation or that these peptides altered stromal growth factor production. In CM cultures, $\mathrm{DR}^{-}$cells are cultured in transwells placed in stromafree wells and receive daily fresh media conditioned by marrow stroma present in separate culture vessels. Addition of FN peptides directly to progenitors allowed us to evaluate direct effects of FN peptides on progenitor growth. Addition of FN peptides to the stroma-containing culture vessel allowed us to evaluate the effect of these peptides on stromal growth factor production. When FN peptides were added directly to progenitors, no direct stimulatory effect on CFC recovery or proliferation was observed (Fig. $5 B$ ). Likewise, when FN peptides were added directly to the stroma-containing culture vessel, no stimulatory effect on CFC recovery or proliferation was noted (Fig. $5 \mathrm{C}$ ). These experiments indicate that increased CFC recovery and proliferation observed when FN peptides are continuously present in stroma-contact cultures is not due to a direct stimulation of CFC nor to alterations in the production of soluble factors by the stroma.

\section{Discussion}

Adhesion to the marrow microenvironment serves a variety of functions in human hematopoiesis. Adhesive interactions underlie homing of progenitors to the $\mathrm{BM}$ microenvironment and are likely important for trafficking of cells within the BM compartment $(8,21)$. Growth-regulatory cytokines are produced in the marrow and are bound and concentrated by components of the $\operatorname{ECM}(1,22,23)$. Adhesive interactions may be important for anchoring progenitors in close proximity to cytokines in what has been termed a "stem-cell niche" or "local-area-network" (24). Furthermore, adhesive interactions may actually modify the response of cells to small concentrations of growth factors (24). It has recently been recognized that adhesion receptors can function as signal transduction molecules that transmit information into a variety of cells (3). Adhesion, per se, may therefore have profound effects on cellular proliferation or differentiation. This led us to study the role of direct growth and differentiation-modulating signals resulting from specific adhesion receptor-ligand interactions in stroma-dependent marrow cultures.

The role of adhesive interactions in hematopoiesis has inherently been difficult to assess since progenitors are functionally defined in vitro as cells that give rise to colonies or cells that can initiate long-term cultures. Although highly enriched in CD34+ subpopulations, cells with clonogenic and long-term culture initiating cell capacity represent only a small (1-5\%) fraction of these purified CD34+ subpopulations $(6,25)$. Furthermore, growth of progenitors in complex long-term stromabased cultures is mediated by multiple cytokine and adhesionmediated signals that may act simultaneously, sequentially, or at different stages of differentiation.

We used $\left[{ }^{3} \mathrm{H}\right]$ thymidine suicide assays to study the effect on CFC proliferation of adhesive interactions between CFC in the CD34+ population and stroma. We demonstrate that physical separation of cells from the stromal layer in stroma-noncontact cultures results in continuous proliferation of CFC throughout the week after feeding, much like nonadherent CFC in standard stroma-contact long-term cultures. This suggests a role for progenitor-stroma contact in restricting or inhibiting progenitor proliferation. We then used modified stromal layers and defined adhesive ligands to delineate the role of adhesion from the effects of inhibitory cytokines on CFC proliferation. These studies demonstrate that decreased proliferation of adherent CFC is, at least in part, the result of adhesion to stromal elements itself, since adhesion to a metabolically inactivated stromal layer in the presence of anti-TGF- $\beta$ antibodies and adhesion to stromal ECM or to the $\mathrm{COOH}$-terminal heparin-binding domain of FN inhibited CFC proliferation. Specific adhesion to ECM or FN is required since nonspecific adhesion to poly-L-lysine failed to inhibit CFC proliferation. These studies suggest that proliferation of clonogenic cells is inhibited after adhesion to stroma, stromal ECM, or the heparin-binding domain of FN and suggest that proliferation inhibition may be the result of signals transmitted into cells by FN receptors. It is possible, however, that phenotypic differences exist between adherent and nonadherent cells that account for the increased adhesiveness and decreased proliferation of adherent cells. Such differences could include an increased expression of FN receptors or an increased activation state of these receptors on progenitor cell subsets. Studies that characterize the phenotype of adherent cells and examine the effect of recently described activating antibodies to the $\beta 1$ 


\section{CFC RECOVERY}

$\mathbf{A}$

\section{FN Peptides Added to Stroma-Contact Cultures}
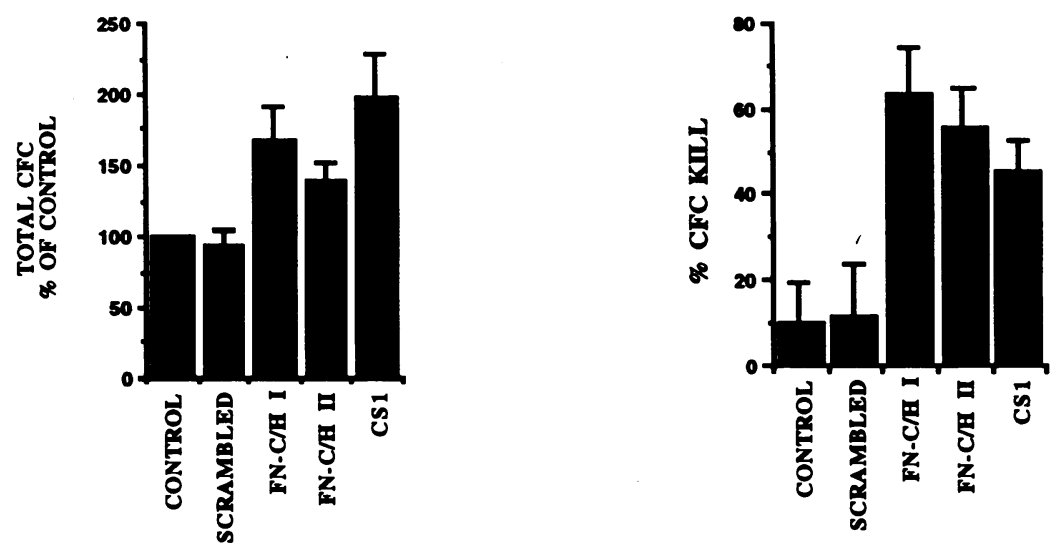

B

\section{Conditioned-Media Cultures: FN Peptides Added to Cells Grown in Conditioned Media}
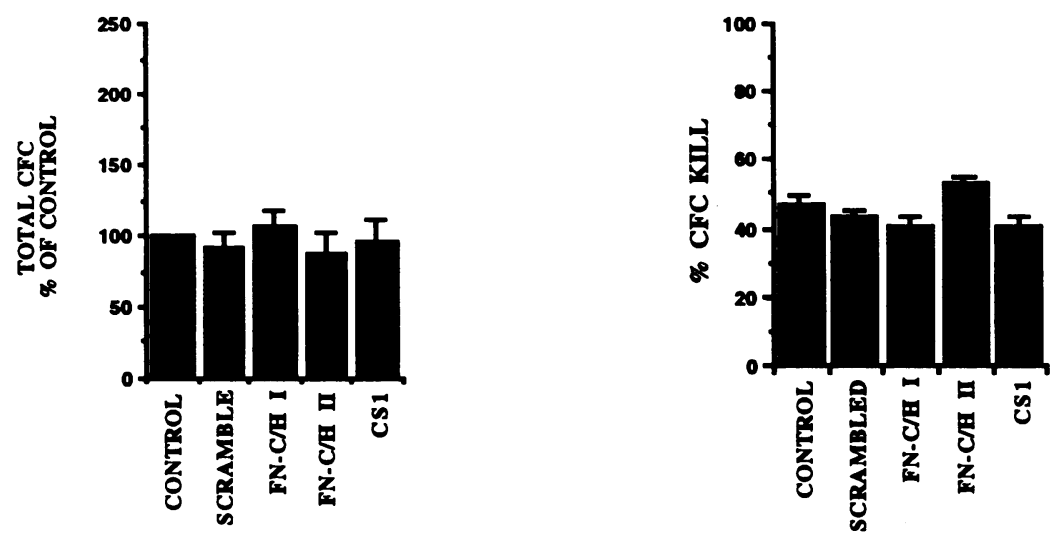

$\mathbf{C}$
Culture Vessels From Which Conditioned Media is Obtained

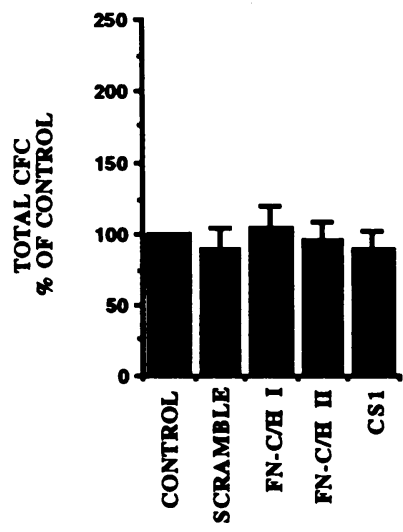

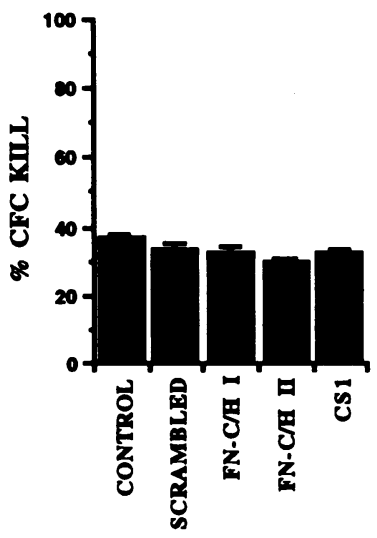

Figure 5. Addition of synthetic FN peptides to long-term stromacontact cultures disrupts adhesionmediated proliferation inhibition. $5,000-10,000 \mathrm{DR}^{-}$cells $(n=6)$ were preincubated with synthetic FN peptides derived from the heparin-binding domain of FN (FN$\mathrm{C} / \mathrm{H} \mathrm{I}, \mathrm{FN}-\mathrm{C} / \mathrm{H}-\mathrm{II}$, or CS1 ) before plating in long-term stroma-contact $(A)$ or $\mathrm{CM}$ ( $B$ and $C$ ) cultures. Untreated cells and cells to which a scrambled version of $\mathrm{FN}-\mathrm{C} / \mathrm{H}$ II was added served as controls. Additional peptide was added three times per week directly to the stromal culture $(A)$, directly to cells in conditioned-media cultures $(B)$, or to the stromal flasks from which CM was obtained $(C)$.

During week 5 of culture, overall recovery of CFC was determined by replating cells from all cultures in methylcellulose progenitor assay. On day 7 after feeding during week 5 , proliferation of adherent CFC in stroma-contact cultures $(A, n=4)$ and CFC in CM cultures ( $B$ and $C, n=3$ ) was evaluated via $\left[{ }^{3} \mathrm{H}\right]$ thymidine suicide assay. ( $A$ ) Stroma-contact cultures. Total CFC/5000 DR cells in control cultures $=55 \pm 13$. Percent of $\mathrm{CFC}$ in adherent fraction: control, $38 \pm 6 \%$; scrambled, $35 \pm 5 \%$; FN-C/H I, $31 \pm 4 \%$; FN-

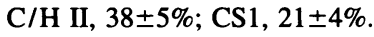
Statistical analysis: $\mathrm{CFC}$ number compared with control: $\mathrm{FN}-\mathrm{C} / \mathrm{H}$ I $P=0.02$, FN-C/H II $P=0.021$, CS1 $P=0.027$. Proliferation (\% kill) of adherent CFC compared with control: FN-C/H I $P=0.05$, FN-C/H II $P=0.033$, CS $1 P$ $=0.036$. $(B)$ Conditioned media cultures with peptide added directly to cells. Total CFC/ $5000 \mathrm{DR}^{-}$cells in control cultures $=288 \pm 40$ CFC. No significant difference in total CFC recovery or proliferation was observed. $(C)$ Conditioned media cultures with peptide added to the stromal culture vessel from which conditioned media was obtained. Total $\mathrm{CFC} / 5000 \mathrm{DR}^{-}$cells $=280 \pm 40$ CFC. No significant difference in total CFC recovery or proliferation was observed. integrin (26) on adhesion and subsequent growth inhibition are currently underway.

The observation that adhesion to the heparin-binding domain of FN inhibits CFC proliferation and that monomeric $F(a b)$ fragments of the monoclonal anti- $\alpha 4$ antibody, HP2/4, block the inhibition of proliferation of stroma-adherent CFC implicate the VLA-4 integrin as one receptor responsible for transmitting proliferation inhibitory signals to hematopoietic progenitors. Monomeric $\mathrm{F}(\mathrm{ab})$ fragments were used instead of intact IgG since cross-linking of VLA-4 by the monoclonal anti$\alpha 4$ antibody HP2/4, itself, like adhesion to FN, results in signal transduction such as induction of immediate-early genes in 
monocytes (27). In contrast, the HP2/4 monomeric F(ab) fragment does not (27). Furthermore, preliminary studies from our group indicate that antibody-induced cross-linking of the $\alpha 4$ receptor using intact HP2/4 antibody inhibits hematopoietic progenitor proliferation (28). The latter observation further strengthens our hypothesis that engagement of the $\alpha 4$ adhesion receptor provides an inhibitory signal for progenitor proliferation. Finally, addition of synthetic FN peptides, representing specific cell attachment sites, to a more physiologic Dextertype stroma-contact culture increased the recovery of CFC and the proliferation of adherent progenitors. Therefore, synthetic peptide-induced disruption of specific adhesive events, involving FN receptors on hematopoietic cells, may disrupt adhesion mediated proliferation inhibition resulting from progenitorstroma interactions. Taken together, these studies implicate further the $\alpha 4 \beta 1$ integrin and possibly the CD44 proteoglycan on hematopoietic cells in mediating proliferation-inhibitory signal transduction events.

Studies in other biological systems suggest that adhesion, per se, may alter proliferation and differentiation in both a positive and negative fashion. In $\mathrm{T}$ cells, $\beta 1$ integrin engagement by its naturally occurring ligand or by monoclonal antibody cross-linking serves as a costimulatory signal for proliferation and can result in tyrosine phosphorylation of intracellular proteins $(14,29)$. Conversely, adhesion to FN inhibits terminal differentiation of keratinocytes and inhibits Schwann cell proliferation $(15,30)$. Overexpression of the $\alpha 5 \beta 1$ integrin reduces the ability of Chinese hamster ovary cells to grow in soft agar (31). These studies suggest that adhesion receptor-ligand binding, and in particular, engagement of integrins, may play a critical role in the control of cell proliferation.

Little is known regarding signaling through integrins' or CD44 in hematopoietic progenitors. However, both receptors have well-known "outside-in" signaling functions. Since the short cytoplasmic tail of integrins is connected to the actin cytoskeleton, cytoskeletal reorganization may be required for signal transduction (32). Integrin engagement also results in tyrosine phosphorylation (of molecules such as paxillin, tensin, and p120FAK), increased intracellular calcium, cytoplasmic alkalinization, induction of immediate-early gene transcription, and modulation of affinity or specificity of other receptors (3, 32). Similarly, CD44 can mediate interactions with the cytoskeleton, associate with protein kinase $\mathrm{A}$ and $\mathrm{C}$, and may have a GTP binding and GTPase-like activity $(33,34)$. How signaling through these molecules might lead to inhibition of hematopoietic progenitor proliferation is currently under study.

Although we demonstrate here one receptor-ligand interaction that inhibits proliferation of hematopoietic progenitors, orderly hematopoiesis is a complex process involving a variety of adhesive and cytokine-mediated interactions. Therefore, additional receptor-ligand interactions may play a role in the control of progenitor proliferation or differentiation. In addition, it is possible that growth-promoting and growth-inhibitory cytokines may modulate these adhesive interactions. For example, progenitors use the $\alpha 4 \beta 1$ integrin to adhere to the CS1 site in the heparin-binding domain of FN (13). However, progenitors may preferentially recognize VCAM after expression of VCAM is induced on marrow stromal cells (16). The growth-promoting cytokine IL-1 increases VCAM expression (16), whereas the growth-inhibitory cytokine, TGF- $\beta$, downregulates VCAM expression on stromal cells in lymphoid and myeloid long-term marrow cultures (35), (Hurley, R. W., unpublished observa- tions). Whether adhesion to VCAM, a cell-surface receptor, has effects on progenitor proliferation similar to adhesion to FN, an ECM protein, remains unknown. In addition, recent studies from our group demonstrate that negative regulatory cytokines, such as TFG- $\beta$ and macrophage inflammatory protein $1 \alpha$ may increase the adhesion of committed progenitors to BM stroma (36). It is therefore possible that, aside from their direct inhibitory effects on hematopoietic progenitor proliferation, TGF- $\beta$ and macrophage inflammatory protein $1 \alpha$ may further inhibit proliferation by reinforcing direct adhesion-mediated proliferation inhibition.

The importance of adhesion-mediated proliferation inhibition becomes clear when examining the stem-cell malignancy, chronic myelogenous leukemia (CML). CML is characterized by a defect in adhesion of progenitors to BM stroma and premature release of malignant progenitors into the peripheral circulation $(37,38)$. In contrast to normal progenitors, stroma-adherent CML progenitors proliferate continuously in stroma-contact cultures (39). This in vitro proliferative behavior of CML progenitors is reminiscent of that of normal progenitors cultured in the presence of synthetic FN peptides in stroma-contact cultures as described here. Indeed, CML progenitors are defective in their adhesion to FN and to FN proteolytic fragments, and this defect in adhesion may be caused by dysfunctional integrin receptors (40). Lack of interaction through FN receptors with the marrow microenvironment may thus, in part, underlie the abnormal proliferation of malignant CML progenitors much like what is seen in stromal cultures described here in which specific FN receptor mediated progenitor-stroma interactions are interrupted. This further strengthens our hypothesis that specific adhesive interactions of progenitors with the marrow microenvironment may be responsible for the transmission of growthinhibitory signals.

\section{Acknowledgments}

We thank Brad Anderson for his excellent technical help.

Supported in part by National Institutes of Health grants RO1-CA4581401, RO1-HL-49930-01A2, RO1-HL-48738-01, and PO1-CA21737. We also acknowledge the support of the Gamble-Skagmo Foundation, the Paul Christiansen Foundation, the University of Minnesota Bone Marrow Transplantation Research Fund, the Leukemia Task Force, the Children's Cancer Research Fund, the Leukemia Society of America, the Fundacion Internacional Jose Carreras Para La Lucha Contra La Leukemia, and the University of Minnesota Hospitals and Clinic.

\section{References}

1. Eaves, C. J., J. D. Cashman, R. J. Kay, G. J. Doughtery, T. Otsuka, L. A. Gaboury, D. E. Hogge, P. M. Lansdorp, A. C. Eaves, and R. K. Humphries. 1991. Mechanisms that regulate the cell cycle status of very primitive hematopoietic cells in long-term human marrow cultures. II. Analysis of positive and negative regulators produced by stromal cells within the adherent layer. Blood. 78:110117.

2. Verfaillie, C., R. Hurley, R. Bhatia, and J. B. McCarthy. 1994. Role of bone marrow matrix in normal and abnormal hematopoiesis. Crit. Rev. Oncol. Hematol. 16:201-224.

3. Juliano, R. L., and S. Haskill. 1993. Signal transduction from the extracellular matrix. J. Cell Biol. 120:577-585.

4. Cashman, J., A. C. Eaves, and C. J. Eaves. 1985. Regulated proliferation of primitive hematopoietic progenitor cells in long term human marrow cultures. Blood. 66:1002-1005.

5. Cashman, J. D., A. C. Eaves, E. W. Raine, R. Ross, and C. J. Eaves. 1990. Mechanisms that regulate the cell cycle status of very primitive hematopoietic cells in long-term human marrow cultures. I. Stimulatory role of a variety of mesenchymal cell activators and inhibitory role of TGF $\beta$. Blood. 75:96-101.

6. Verfaillie, C. M. 1992. Direct contact between human primitive hematopoi- 
etic progenitors and bone marrow stroma is not required for long-term in-vitro hematopoiesis. Blood. 79:2821-2826.

7. Weinstein, R., M. A. Riordan, K. Wenc, S. Kreczko, M. Zhou, and N. Dainiak. 1989. Dual role of fibronectin in hematopoietic differentiation. Blood. 73:111-116.

8. Williams, D. A., M. Rios, C. Stephans, and V. P. Patel. 1991. Fibronectin and VLA-4 in haematopoietic stem cell-microenvironment interactions. Nature (Lond.). 352:438-441.

9. Verfaillie, C. M., J. B. McCarthy, and P. B. McGlave. 1991. Differentiation of primitive human multipotent hematopoietic progenitors into single lineage clonogenic progenitors is accompanied by alterations in their interactions with fibronectin. J. Exp. Med. 174:693-703.

10. Kerst, J. M., J. B. Sanders, I. C. M. Slaper-Cortenbach, M. C. Doorakkers, B. Hoolbrink, R. H. J. van Oers, A. E. G. Kr. von dem Borne, and C. E. van de Schoot. 1993. $\alpha 4 \beta 1$ and $\alpha 5 \beta 1$ are differentially expressed during myelopoiesis and mediate the adherence of human $\mathrm{CD} 34^{+}$cells to fibronectin in an activationdependent way. Blood. 81:344-351.

11. Wayner, E. A., A. Garcia-Pardo, M. J. Humphries, J. A. McDonald, and W. G. Carter. 1989. Identification and characterization of the T lymphocyte receptor for an alternative cell attachment domain (CS1) in plasma fibronectin. J. Cell Biol. 109:1321-1330.

12. McCarthy, J, B, A P N Skubitz, Q Zhao, X Yi, D. J Mickelson, D. J. Klein, and L. T. Furcht. 1990. RGD-independent cell adhesion to the carboxy terminal heparin binding fragment of fibronectin involves heparin-dependent and independent activities. J. Cell Biol. 110:777-791.

13. Verfaillie, C. M., A. Benis, G. Iida, P. B. McGlave, and J. B. McCarthy. 1994. Adhesion of committed human hematopoietic progenitors to synthetic peptides from the C-terminal heparin binding domain of fibronectin: cooperation between the integrin a4bl and the CD44 adhesion receptor. Blood. 84:18021811.

14. Shimizu, Y., G. A. van Seventer, K. J. Horgan, and S. Shaw. 1990 Costimulation of proliferative responses of resting $\mathrm{CD}^{+} \mathrm{T}$ cells by the interaction of VLA-4 and VLA-5 with fibronectin or VLA-6 with laminin. J. Immunol. 145:59-67.

15. Adams, J. C., and F. M. Watt. 1989. Fibronectin inhibits the terminal differentiation of human keratinocytes. Nature (Lond.). 340:307-309.

16. Simmons, P. J., B. Masinovsky, B. M. Longenecker, R. Berenson, B Torok-Storb, and W. M. Gallatin. 1992. Vascular cell adhesion molecule-1 expressed by bone marrow stromal cells mediates binding of hematopoietic progenitor cells. Blood. 80:388-395.

17. Teixido, J., M. E. Hemler, J. S. Greenberger, and P. Anklesaria. 1992 Role of $\beta 1$ and $\beta 2$ integrins in the adhesion of human $\mathrm{CD} 34^{\mathrm{hi}}$ stem cells to bone marrow stroma. J. Clin. Invest. 90:358-367.

18. Verfaillie, C., K. Blakolmer, and P. McGlave. 1990. Purified primitive human hematopoietic progenitor cells with long-term in-vitro repopulating capacity adhere selectively to irradiated bone marrow stroma. J. Exp. Med. 172:509 520 .

19. Roberts, R. A., E. Spooncer, E. K. Parkinson, B. I. Lord, T. D. Allen, and T. M. Dexter. 1987. Metabolically inactive 3T3 cells can substitute for marrow stromal cells to promote the proliferation and development of multipotent haemopoietic stem cells. J. Cell. Physiol. 132:203-214.

20. Schibler, K. R., Y. C. Yang, and R. D. Christensen. 1992. Effects of Interleukin-11 on cycling status and clonogenic maturation of fetal and adul hematopoietic progenitors. Blood. 80:900-903.

21. Aizawa, S., and M. Tavassoli. 1988. Molecular basis of the recognition of intravenously transplanted hemopoietic cells by bone marrow. Proc. Natl. Acad. Sci. USA. 85:3180-3183.

22. Gordon, M. Y., G. P. Riley, S. M. Watt, and M. F. Greaves. 1987 Compartmentalization of a haematopoietic growth factor (GM-CSF) by glycos- aminoglycans in the bone marrow microenvironment. Nature (Lond.). 326:403405 .

23. Roberts, R., J. Gallagher, E. Spooncer, T. D. Allen, F. Bloomfield, and T. M. Dexter. 1988. Heparan sulfate bound growth factors: a mechanism for stromal cell mediated haematopoiesis. Nature (Lond.). 332:376-378.

24. Williams, D. A. 1993. Ex-vivo expansion of hematopoietic stem and progenitor cells - robbing Peter to pay Paul? Blood. 81:3169-3172.

25. Sutherland, H. J., C. J. Eaves, P. M. Lansdorp, J. D. Thacker, and D. E. Hogge. 1991. Differential regulation of primitive human hematopoietic cells in long-term cultures maintained on genetically engineered murine stromal cells. Blood. 78:666-672.

26. Kovach, N. L., T. M. Carlos, E. Lee, and J. H. Harlan. 1992. A monoclonal antibody to $\beta 1$ integrin (CD29) stimulates VLA-dependent adherence of leukocytes to human umbilical vein endothelial cells and matrix components. J. Cell Biol. 116:499-502.

27. Yurochko, A. D., D. Y. Liu, D. Eierman, and S. Haskill. 1992. Integrins as a primary signal transduction molecule regulating monocyte immediate-early gene induction. Proc. Natl. Acad. Sci. USA. 89:9034-9038.

28. Hurley, R. W., J. B. McCarthy, and C. M. Verfaillie. 1994. Monoclonal antibody induced clustering of the alpha-4 integrin inhibits hematopoietic progenitor proliferation. Exp. Hematol. 22:767. (Abstr.)

29. Nojima, Y., D. M. Rothstein, K. Sugita, S. F. Schlossman, and C. Morimoto. 1992. Ligation of VLA-4 on T cells stimulates tyrosine phosphorylation of 105kD protein. J. Exp. Med. 175:1045-1053

30. Muir, D., and M. Manthorpe. 1992. Stromelysin generates a fibronectin fragment that inhibits Schwann cell proliferation. J. Cell Biol. 116:177-185.

31. Giancotti, F. G., and E. Ruoslahti. 1990. Elevated levels of the $\alpha 5 \beta$ fibronectin receptor suppress the transformed phenotype of Chinese hamster ovary cells. Cell. 60:849-859.

32. Hynes, R. O. 1992. Integrins: versatility, modulation, and signalling in cell adhesion. Cell. 69:11-25.

33. Kalomiris, E. L., and L. Y. W. Bourguignon. 1989. Lymphoma protein kinase $\mathrm{C}$ is associated with the transmembrane glycoprotein $\mathrm{Gp85}$ and may function in Gp85-ankyrin binding. J. Biol. Chem. 264:8113-8119.

34. Lokeshwar, V. B., and L. Y. W. Bourguignon. 1992. The lymphoma transmembrane glycoprotein Gp85 (CD44) is a novel guanine nucleotide-binding protein which regulates Gp85 (CD44)-ankyrin interaction. J. Biol. Chem. 267:22073-22078.

35. Dittel, B. N., J. B. McCarthy, E. A. Wayner, and T. W. LeBien. 1993 Regulation of human B cell precursor adhesion to bone marrow stromal cells by cytokines that exert opposing effects on the expression of vascular cell adhesion molecule-1 (VCAM-1). Blood. 81:2272-2282.

36. Migas, J., R. W. Hurley, and C. M. Verfaillie. 1994. MIP1 $\alpha$ and TGF- $\beta$ increase adhesion of normal committed progenitors to marrow stroma. Exp. Hematol. 22:736. (Abstr.)

37. Gordon, M. Y., C. R. Dowding, G. P. Riley, J. M. Goldman, and M. F Greaves. 1987. Altered adhesive interactions with marrow stroma of hematopoietic progenitor cells in chronic myelogenous leukemia. Nature (Lond.). 328:342344.

38. Verfaillie, C. M., J. B. McCarthy, and P. B. McGlave. 1992. Mechanisms underlying abnormal trafficking of malignant progenitors in chronic myelogenous leukemia: decreased adhesion to stroma and fibronectin but increased adhesion to the basement membrane components laminin and collagen type IV. J. Clin. Invest. 90:1232-1239.

39. Eaves, A. C., J. D. Cashman, L. A. Gaboury, D. K. Kalousek, and C. J. Eaves. 1986. Unregulated proliferation of primitive chronic myeloid leukemia progenitors in the presence of normal marrow adherent cells. Proc. Natl. Acad. Sci. USA. 83:5306-5310.

40. Bhatia, R., E. A. Wayner, P. G. McGlave, and C. M. Verfaillie. 1994. Interferon- $\alpha$ restores normal adhesion of chronic myelogenous leukemia hematopoietic progenitors to bone marrow stroma by correcting impaired $\beta 1$ integrin receptor function. J. Clin. Invest. 94:384-391. 